\title{
Interview Dr. Angelika C. Bullinger-Hoffmann, TU Chemnitz
}

\section{Interview Question}

Crisis-driven innovation opens up a whole range of opportunities for new trajectories. What role does social capital play in this regard? Do we have to re-consider the way we measure innovation performance if we talk about open innovation for the greater good? If so, how could such an indicator look like?

\section{Author: Dr. Angelika C. Bullinger-Hoffmann, TU Chemnitz}

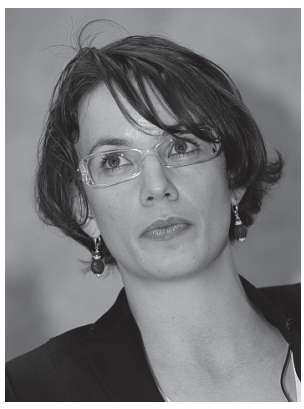

The phenomenon 'crisis-driven social innovation' can be regarded on an individual and on a societal level.

On an individual level, crisis-driven social innovation is triggered by a crisis in the direct environment of the person, i.e. themselves or their close personal relations are affected. An example is a lifethreatening disease that requires innovative activity by the person and his or her environment to come up with novel solutions to the altered life situation. We have observed with the German project 'GemeinsamSelten' (www.gemeinsamselten.de) ${ }^{1}$ and the US project 'My HeartMap Challenge' (www.myheartmap.com) that individuals are highly innovative in this situation of crisis. Simultaneously, we found that individuals develop strong relationships of mutual trust and support among each other - as academics, we use the term 'relational social capital'.

On a societal level, crisis-driven social innovation is caused by a crisis which affects the society of a region as a whole. For instance, the outsourcing of workplaces in the field of apparel severely affects regions in Southern Germany. This kind of crisis requires innovative actions by governments, entrepreneurs and the general public alike. The start-up company 'manomama'2 (www.manomama.de) strives to bring back apparel production to Southern Germany. Its product innovation of ecologically correct clothing triggers a set of social innovation by providing jobs for persons who are beyond 40 or have a low level of qualification. Support by the general public is high - price premiums are well accepted and the sole marketing activity of 'manomama' is word of mouth by the supporters.

Angelika Bullinger-Hoffmann is Acting Professor of Human Factors and Ergonomics at the Technische Universität Chemnitz as well as assistant professor at the School of Business and Economics at the University of Erlangen-Nuremberg.

1 Bullinger, A.C./Rass, M./Adamczyk, S./Moeslein, K.M./Sohn, S. (2012): Open innovation in health care: Analysis of an open health platform, in: Health policy, Vol. 105, pp. 165-175.

Bullinger, A.C./Rass, M./Moeslein, K.M. (2012): Towards Open Innovation in Health Care, in: Proceedings of European Conference on Information Systems 2012, Barcelona (paper 444).

2 Plieth, H./Bullinger, A.C./Hansen, E.G. (2012): Sustainable Entrepreneurship in the Apparel Industry The Case of Manomama, in: Journal for Corporate Citizenship, Vol. 45 (spring 2012), pp. 121-134. 